\title{
Green Tea Is a Poor Contributor to Tissue Folate in a Folate Depletion-Repletion Rat Model
}

\author{
Kaori Endoh $^{1}$, Michael Fenech ${ }^{2}$, Keizo Umegaki $^{3 *}$ \\ ${ }^{1}$ Division of Nutritional Sciences, School of Food and Nutritional Sciences, University of Shizuoka, Shizuoka, Japan; ${ }^{2}$ CSIRO Food \\ and Nutritional Sciences, Adelaide, Australia; ${ }^{3}$ Information Center, National Institute of Health and Nutrition, Tokyo, Japan. \\ Email: umegaki@nih.go.jp
}

Received November $26^{\text {th }}, 2012$; revised January $9^{\text {th }}, 2013$; accepted January $16^{\text {th }}, 2013$

\begin{abstract}
Green tea contains folate and epigallocatechin gallate (EGCg), which is suggested to be an antifolate. In this study, we examined whether green tea was a good source of folate in a folate depletion/repletion rat model. Rats fed a folate deficient diet for 4 weeks were supplied with folate for 7 days, and then folate repletion effects were evaluated in terms of increase in total folate level in plasma, liver, and bone marrow and decrease in plasma homocysteine level. In this model, the folic acid treatment effect was observed to be dose-dependent and an appropriate dose of folic acid was $40 \mu \mathrm{g} / \mathrm{kg} /$ day or greater. Based on this finding, green tea as well as spinach, chicken liver, and folic acid as a reference were applied to this model. Increase in tissue folate level in response to the food samples varied among tissues, with bone marrow showing the smallest response. Increase in tissue folate level was in the order of spinach > chicken liver $>$ green tea, which produced only a slight increase in tissue folate level and further diminished bone marrow folate level. EGCg administered by intragastric gavage at an approximate dose of $8 \mathrm{mg} / \mathrm{kg}$ did not attenuate the increase in tissue folate level when repletion was performed with folic acid. These results suggested that green tea is a poor source of food folate, but EGCg in green tea at a low dose has little effect on folic acid absorption.
\end{abstract}

Keywords: Green Tea; Food Folate; Folic Acid; Epigallocatechin Gallate; Rat Model

\section{Introduction}

Folate has a role in the transfer and utilization of onecarbon groups and is involved in the de novo synthesis of nucleic acid bases and amino acids. Folate deficiency can lead to megaloblastic anemia [1], and low periconceptional folate status in women is related to an increased risk of fetal abnormalities such as neural tube defects (NTDs) [2]. In addition, low folate status leads to an increase in plasma homocysteine level, which is a risk factor for atherosclerosis, and impairs DNA synthesis and repair, resulting in increased DNA damage and consequently cancer initiation $[3,4]$.

Folate naturally occurring in food ("natural folate") mainly occurs in the polyglutamated form, but is converted to the monoglutamate form before absorption by deconjugation in the intestine. In contrast, synthetic folic acid (pteroylmonoglutamic acid), which is used for dietary supplementation and in fortified food, is the most oxidized and stable form, and is highly bioavailable. The bioavailability of folic acid is estimated to be, on average, about 2 times that of natural folate, but this varies de-

${ }^{*}$ Corresponding author. pending on the food $[1,5]$. Excess intake of folic acid is of concern due to the possibility masking of vitamin $B_{12}$ deficiency [1], increasing the risk of cancer growth when a tumor is present [4], and childhood asthma when taken in late pregnancy [6]. Generally, it is desirable to obtain folate from food because this approach minimizes excessive intake of this important vitamin. However, bioavailability of natural folate from foods is reported to vary greatly [5] due to differences between foods in the form of folate present, the food matrix in which it exists, and the presence of factors affecting its absorption and metabolism.

Intake of green tea (Camellia sinensis) has attracted a great deal of attention because it has been suggested to have health benefits in terms of protecting against vascular disease and some types of cancer due to the presence of catechins [7]. Green tea also contains natural folate and is regarded as one of the sources of folate, along with vegetables and fruit, in the Japanese diet [8]. However, green tea catechins including (-)-epigallocatechin gallate (EGCg) are reported to inhibit uptake of folic acid by Caco-2 cell monolayers [9] and inhibit dihydrofolate reductase (DHFR) activity in vitro [10]. Dihydrofolate 
reductase is an important enzyme because it catalyzes the reduction of folic acid to 7,8-dihydrofolate (DHF) and 5,6,7,8-tetrahydrofolate (THF), which acts as a coenzyme for several one-carbon group transfer reactions after its conversion to 5,10-methylenetarthydrofolate and 5-methyltetrahydro-folate [10]. A cross-sectional study reported a correlation between low serum folate concentration and high consumption of green tea or oolong tea during pregnancy [11]. Further, intake of green tea extract at $0.9 \mathrm{~g} /$ day has been shown to decrease maximum concentration and area under the blood concentration time curve of folic acid in human subjects [12]. On the other hand, consumption of green tea catechin (approximately $670 \mathrm{mg} /$ day) did not influence plasma folate concentration in healthy men, and only high-dose green tea catechins $(0.5 \%$ in diet $)$ simultaneously added to folic acid in the diet decreased serum folic acid level in rats [13]. Accordingly, it remains unclear whether 1) natural folate in green tea is bioavailable, and 2) $\mathrm{EGCg}$ at the low dose found in green tea attenuates folic acid utilizetion in vivo. In this study, we examined the above questions in a modified folate depletion/repletion rat model [14].

\section{Materials and Methods}

\subsection{Chemicals and Diet}

Folic acid and EGCg were obtained from Wako Pure Chemical Ltd. (Osaka, Japan). For the folate microbeological assay, folinic acid calcium salt pentahydrate, Lactobacillus rhamnosus (strain ATCC 27773) and folic acid casei medium were obtained from Fluka (Buchs, Switzerland), the American Type Culture Collection (Rockville, MD, USA), and Becton Dickinson (Sparks, MD, USA), respectively. A folate-deficient diet (Dyets version of the Clifford/Kuory folate-deficient amino acid rodent diet, \#517777) was purchased from Dyets (Bethlehem, PA, USA). This diet is composed of folate-free amino acids with the recommended amount of vitamins except folate, and the addition of $1 \%$ succinylsulfathiazole to minimize intestinal folate synthesis. Powdered green tea (matcha), spinach, and chicken liver were purchased at local grocery stores (Tokyo, Japan). The spinach and chicken liver were lyophilized, ground finely with a mortar and pestle, and stored at $-80^{\circ} \mathrm{C}$ until use. Total folate content in food samples ( $\mu \mathrm{g} / \mathrm{g}$ dry weight) was 10.2 in powdered green tea, 23.2 in freeze-dried spinach, and 57.0 in chicken liver. Food samples or folic acid were added to the folate-deficient diet at a folate concentration of $800 \mu \mathrm{g} / \mathrm{kg}$ diet. The percentage of food sample in the diet was $7.8 \%$ for powdered green tea, $3.4 \%$ for freeze-dried spinach, and $1.4 \%$ for chicken liver. The catechin content in powdered green tea was $22 \mathrm{mg} / \mathrm{g}$, and these catechins were composed of 50\% EGCg, 14\% (-)-epicatechin gallate, 13\% (-)-epigallocatechin, 13\% $(+)$-catechin, 6\% (-)-epicatechin, and 3\% (-)-catechin gallate.

\subsection{Animals}

Male Wistar rats purchased from Japan Clea (Tokyo, Japan) were housed individually in wire bottomed cages in a room maintained at a constant temperature of $23^{\circ} \mathrm{C} \pm$ $1^{\circ} \mathrm{C}$ with a 12-hour light-dark cycle. Following the experiments, the rats were euthanized with sodium pentobarbital, blood was taken from the abdominal aorta with a heparinized syringe, and the liver, femurs, and tibiae were removed. Bone marrow cell samples were prepared from the femurs and tibiae according to a method reported previously [15]. All procedures were in accordance with the National Institute of Health and Nutrition guidelines for the Care and Use of Laboratory Animals, and they were approved by the ethical committee of the National Institute of Health and Nutrition.

\subsection{Folate Depletion/Repletion Model}

The folate depletion/repletion procedure was performed as reported previously [14] with the exception that the present study used a shorter 7-day repletion period, in order to determine the initial difference in how folate in diverse test samples is incorporated into the body. Rats (4 - 5 weeks old) were given ad libitum access to a folate-deficient diet for 4 weeks, and then given the same diet with supplementary folic acid or food samples for 7 days (each group consisted of 5 - 6 rats). A preliminary study showed that plasma folate transiently increased from 0.5 to 6 hours after an excess folic acid administration $(330 \mu \mathrm{g} / \mathrm{kg}$ body weight), but returned to the basal level at 8 hours. Based on this finding, blood and tissue samples were taken 24 hours after each intragastric gavage administration of folic acid, or after overnight fasting when dietary folate supplementation was given. During the study, body weights and dietary intakes were measured every day.

There were 4 parts to the study (Figure 1). In the timedependent study, the folate-depleted rats $(n=6)$ were administered folic acid daily by intragastric gavage. The folic acid was dissolved in $0.1 \mathrm{M}$ sodium bicarbonate at a dose of $330 \mu \mathrm{g} / \mathrm{kg}$ body weight, and blood was taken every day 24 hours after each folic acid administration. In the dose-response study, the folate-depleted rats were divided into 4 groups ( $\mathrm{n}=5-6)$ to be administered one of 4 doses of folic acid daily $(0,4,40$, or $400 \mu \mathrm{g} / \mathrm{kg}$ body weight/day) by intragastric gavage. In the dietary folate supplementation study, the folate-depleted rats were divided into 5 groups $(\mathrm{n}=5-6)$ : one group underwent monitoring of folate status in the depletion phase, and the 
other 4 were fed a diet containing powdered green tea, spinach, chicken liver, or folic acid. Folate intake in each group was adjusted from the amount of food intake during the previous days (about $11.5 \mathrm{~g} /$ day), and the calculated dose was set at $40 \mu \mathrm{g} / \mathrm{kg}$ body weight. The powdered green tea diet contained about $1.73 \mathrm{~g}$ of total catechins $/ \mathrm{kg}$ diet, and the estimated total catechin dose was approximately $90 \mathrm{mg} / \mathrm{kg}$ body weight. In the study to evaluate the effect of EGCg on folic acid absorption, folate-depleted rats were divided into 3 groups $(n=5-6)$ to be given folic acid ( $31 \mu \mathrm{g} / \mathrm{kg}$ body weight), EGCg ( 8 $\mathrm{mg} / \mathrm{kg}$ body weight), or folic acid with EGCg (folic acid $31 \mu \mathrm{g}$ and EGCg $8 \mathrm{mg} / \mathrm{kg}$ body weight) daily by intragastric gavage.

\subsection{Analytical Methods}

For hematocrit measurements, blood was transferred to a capillary tube and centrifuged at 10,000 g for 10 minutes. Plasma was prepared by centrifugation at $1500 \mathrm{~g}$ for 15 minutes at $4^{\circ} \mathrm{C}$. Whole blood and plasma were immediately mixed with $0.5 \%$ ascorbic acid to stabilize folate and stored at $-80^{\circ} \mathrm{C}$ until folate analysis. The liver and bone marrow cell samples were homogenized or sonicated with 9 volumes of folate extraction buffer $(50 \mathrm{mM}$ phosphate buffer, $0.5 \%$ ascorbic acid, final $\mathrm{pH} 6.1$ ). Total folate concentration in the plasma and conjugase-treated liver and bone marrow samples was analyzed using the microbiological assay described elsewhere [16]. Erythrocyte folate concentration was calculated using the following formula: [whole blood folate- \{plasma folate $\mathrm{x}$ (1hematocrit) $\}] /$ hematocrit. Plasma homocysteine was measured by HPLC using a fluorescence detector [17]. Protein was measured using a BCA protein assay kit (Pierce, Rockford, IL, USA). Folate content in food samples was determined by microbiological assay with the tri-enzyme treatment method [18]. The catechin content in powdered green tea was analyzed by the HPLC method [19].

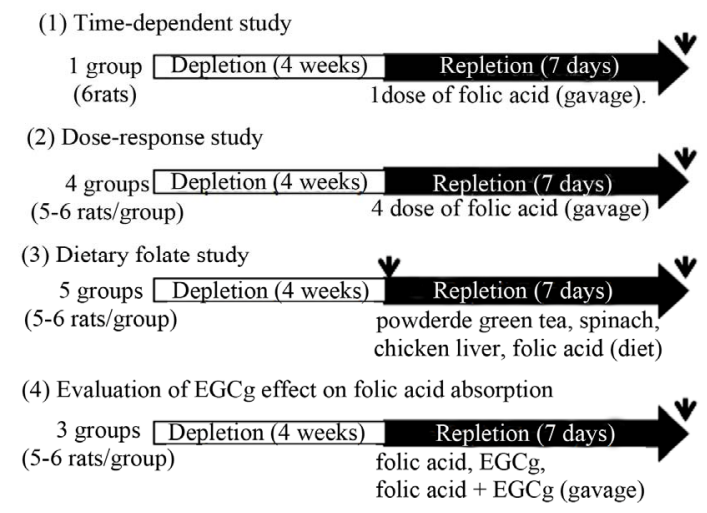

Figure 1. Animal treatment in this study. Rats were sacrificed at the time point shown as an arrow.

\subsection{Statistical Analyses}

Data are presented as the mean \pm standard deviation (SD) for individual groups. Data were analyzed by one-way analysis of variance followed by Dunnett's multiple comparison test. Pearson's correlation coefficient was used to determine the association between tissue folate and plasma total homocysteine. These statistical analyses were performed using GraphPad Prism version 5.01 (GraphPad Software, Inc., San Diego, CA, USA). Values of $p<$ 0.05 were considered significant.

\section{Results}

\subsection{Confirmation of the Folate Depletion/Repletion Rat Model}

Rats were fed a folate-deficient diet for 4 weeks to minimize the background level of plasma folate, and they were then given folic acid at $330 \mu \mathrm{g} / \mathrm{kg}$ body weight/day by intragastric gavage, daily for 7 days. Before administration of folic acid (on day 0 of repletion), plasma folate levels decreased to about $10 \%$ of those in the control diet rats. Levels then increased with the consecutive daily administration of folic acid, by 4 -fold on day 5 and by 7 -fold on day 7 (data not shown). Next, folate-depleted rats (maintained on the folate-deficient diet for 4 weeks) were intragastrically administered various doses of folic acid $(0,4,40$, or $400 \mu \mathrm{g} / \mathrm{kg}$ body weight $/$ day) for 7 days. Changes in body weight during the experimental period are shown in Figure 2. Final body weight was significantly higher in rats given high doses of folic acid. The administration of folic acid increased folate levels in plasma, liver, and bone marrow in a dose-dependent manner and decreased plasma homocysteine level (Figure 3). Plasma total homocysteine level was negatively

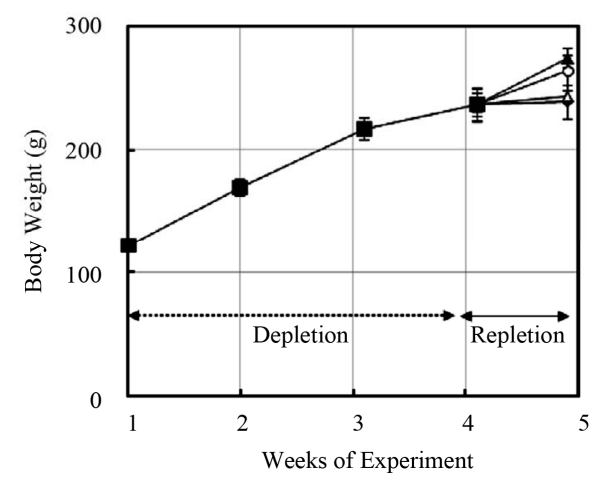

Figure 2. Changes in body weight in rats fed a folate-deficient diet followed by repletion with various doses of folic acid. Rats fed a folate-deficient diet for 4 weeks were intragastrically given various doses of folic acid while maintaining the same folate-deficient diet for 7 days. $\square:$ Depletion phase, $\diamond: 0 \mu \mathrm{g} / \mathrm{kg}$ body weight/day, $\triangle: 4 \mu \mathrm{g} / \mathrm{kg}$ body weight/day, $\circ: 40 \mu \mathrm{g} / \mathrm{kg}$ body weight $/ \mathrm{day}, \Delta: 400 \mu \mathrm{g} / \mathrm{kg}$ body weight/day. Values are mean $\pm S D, n=5$ - 6 . 

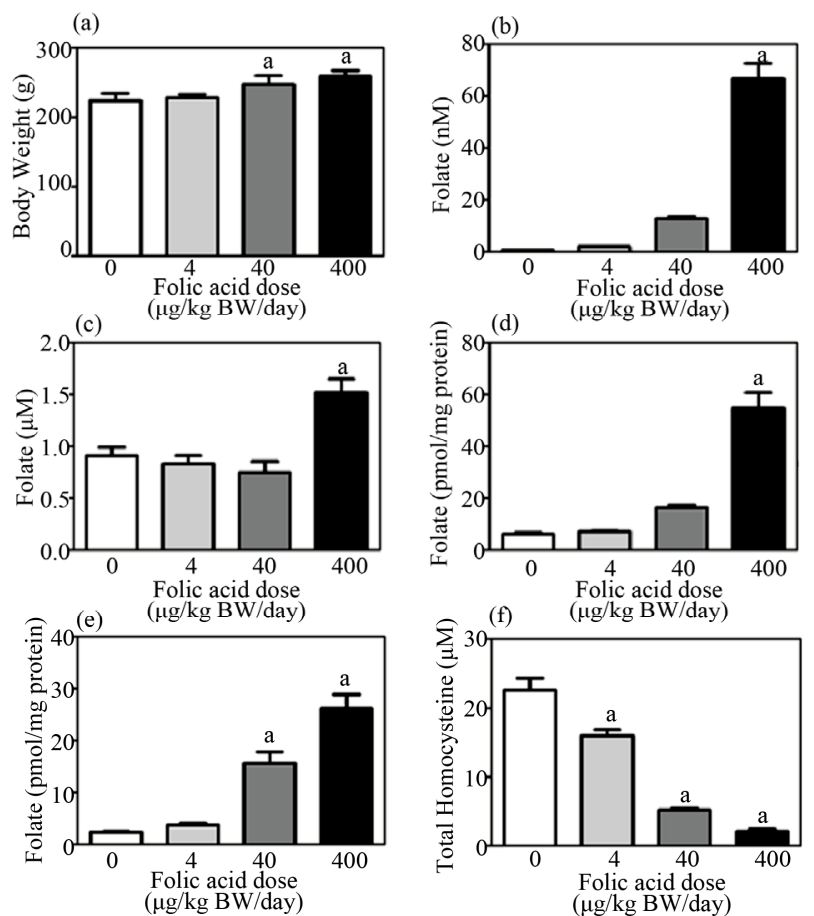

Figure 3. Dose-dependent repletion effect of folic acid on body weight, folate level in tissues, and homocysteine level in plasma in a folate depletion/repletion rat model. Rats fed a folate-deficient diet for 4 weeks were intragastrically given various doses of folic acid $(0,4,40$, or $400 \mu \mathrm{g} / \mathrm{kg}$ body weight/day) for 7 days. (a) Body weight; (b) plasma folate level; (c) erythrocyte folate level; (d) liver folate level; (e) bone marrow folate level; (f) plasma total homocysteine

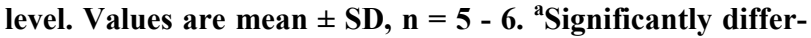
ent from $0 \mu \mathrm{g} / \mathrm{kg}$ body weight/day group $(p<0.05)$.

correlated with folate level in plasma, liver, and bone marrow $(\mathrm{r}=-0.75,-0.74,-0.86$, respectively, $\mathrm{p}<0.05$ for all), but not with erythrocyte folate level, which was only significantly increased at the highest dose of folic acid (i.e., $400 \mu \mathrm{g} / \mathrm{kg}$ body weight/day). Significant changes in folate and homocysteine levels were detected at a folic acid dose of $40 \mu \mathrm{g} / \mathrm{kg}$ body weight/day or greater.

\subsection{Absorption of Powdered Green Tea Folate Relative to Folate in Spinach and Liver, and to Folic Acid}

Diets containing either natural folates or folic acid (with the dose of folate set at $40 \mu \mathrm{g} / \mathrm{kg}$ body weight/day) were given to folate-depleted rats to cause folate repletion. Repletion with folic acid increased plasma and liver folate levels, and decreased plasma homocysteine levels when compared with those in the depletion phase (Table 1). Repletion with natural folate increased folate levels in the plasma and liver, but not in the bone marrow. In contrast to liver and plasma folate levels, bone marrow folate level was further diminished in the rats fed the powdered green tea and chicken liver diets. No significant increase in erythrocyte folate level was detected following the treatments (data not shown). When compared to the folic acid group, relative changes in folate levels among plasma, liver, and bone marrow in the depletion phase ranged from $27 \%$ to $88 \%$ in the spinach group, $-13 \%$ to $42 \%$ in the chicken liver group and $-61 \%$ to $21 \%$ in the powdered green tea group.

\subsection{Effect of EGCg on Folic Acid Utilization}

Influence of low-dose EGCg on folic acid utilization was evaluated in the folate depletion/repletion rat model. The folate-depleted rats were given intragastrically either folic acid $(31 \mu \mathrm{g} / \mathrm{kg}$ body weight), EGCg $(8 \mathrm{mg} / \mathrm{kg}$ body weight), or folic acid with EGCg, on a daily basis. Folic acid administration increased folate concentration in plasma, liver, and bone marrow and decreased plasma homocysteine level (Figure 4). Such changes resulting from folic acid treatment were also detected in the presence of EGCg, suggesting that EGCg at the tested dose did not influence utilization of folic acid.

\section{Discussion}

In the present study, we showed that natural folate from green tea was less bioavailable than folate from other sources in a folate depletion/repletion rat model. Food folate bioavailability estimated based on the increase in plasma and liver folate concentration would be only $17 \%$ $21 \%$ for green tea folate, $27 \%-42 \%$ for chicken liver folate, and $57 \%$ - $88 \%$ for spinach folate, when compared to folic acid as a reference. Our estimation of spinach folate bioavailability is comparable to that reported by Clifford [20], who showed that bioavailability of folate in spinach is $70 \%-90 \%$ of that of folic acid in a depletion/repletion rat model. The present findings suggest that green tea is a poor source of folate and in fact could negatively impact folate status. The present study supports an epidemiological study that showed an association between low plasma folate level and high consumption of green tea [21].

It is important to define the system by which the bioavailability of green tea folate is estimated. In our system, rats were fed a folate-deficient diet for 4 weeks and then given test samples for 7 days, and folate bioavailability was estimated from the increase in the concentration of folate in plasma, liver, and bone marrow and the decrease in the concentration of plasma homocysteine. The folate-depletion period is the same as that described in previous reports [14], but our repletion time was shorter ( 7 days versus 4 weeks). We considered the 7-day repletion period useful to detect initial differences in how folate in diverse test samples is incorporated into the body, and to minimize the effect of substances other than folate in test food samples, particularly those with in 
Table 1. Effect of folate repletion from powdered green tea relative to spinach, chicken liver, and folic acid in a folate depletion/repletion rat model.

\begin{tabular}{|c|c|c|c|c|c|}
\hline \multirow{2}{*}{ Before repletion } & & \multicolumn{4}{|c|}{ After 7 days' repletion } \\
\hline & & Folic acid & Powdered green tea & Spinach & Chicken liver \\
\hline Body weight (g) & $212 \pm 0.2$ & $215 \pm 9.8$ & $211 \pm 7.0$ & $213 \pm 8.7$ & $216 \pm 8.5$ \\
\hline \multicolumn{6}{|l|}{ Folate } \\
\hline Plasma concentration (nM) & $2.17 \pm 0.39$ & $9.28 \pm 2.20$ & $3.41 \pm 1.19^{\mathrm{a}}$ & $6.19 \pm 1.42^{\mathrm{a}}$ & $4.10 \pm 1.37^{\mathrm{a}}$ \\
\hline Change from depletion phase (nM) & - & +7.1 & +1.2 & +4.0 & +1.9 \\
\hline Relative to folic acid group (\%) & & 100 & 17 & 57 & 27 \\
\hline Liver concentration (pmol/mg protein) & $7.33 \pm 1.8$ & $30.9 \pm 6.9$ & $12.3 \pm 2.1^{\mathrm{a}}$ & $28.1 \pm 8.6$ & $17.2 \pm 3.9^{\mathrm{a}}$ \\
\hline Change from depletion phase(pmol/mg protein) & - & +23.6 & +5.0 & +20.1 & +9.9 \\
\hline Relative to folic acid group (\%) & & 100 & 21 & 88 & 42 \\
\hline Bone marrow concentration (pmol/mg protein) & $4.24 \pm 0.7$ & $7.55 \pm 1.7$ & $2.21 \pm 0.4$ & $5.13 \pm 1.0$ & $3.80 \pm 2.0^{\mathrm{a}}$ \\
\hline Change from depletion phase(pmol/mg protein) & - & +3.3 & -2.0 & +0.9 & -0.4 \\
\hline Relative to folic acid group (\%) & & 100 & -61 & 27 & -13 \\
\hline Plasma total homocysteine $(\mu \mathrm{M})$ & $12.4 \pm 1.8$ & $5.2 \pm 1.8$ & $6.1 \pm 0.9$ & $10.6 \pm 1.9^{\mathrm{a}}$ & $9.8 \pm 4.4^{\mathrm{a}}$ \\
\hline Change from depletion phase $(\mu \mathrm{M})$ & - & -7.0 & -6.1 & -1.6 & -2.4 \\
\hline Relative to folic acid group (\%) & & 100 & 87 & 23 & 34 \\
\hline
\end{tabular}

Rats fed a folate-deficient diet for 4 weeks were divided into 5 groups: one group was killed to monitor the folate levels in the depletion phase, and the other 4 groups were given the same folate-deficient diet supplemented with one of 4 test foods/substances (folic acid as a reference, powdered green tea, spinach, and chicken liver) for 7 days. The folate intake dose was set at $40 \mu \mathrm{g} / \mathrm{kg}$ body weight/day. Values are the means $\pm \mathrm{SD}, \mathrm{n}=5-6$. ${ }^{\mathrm{a}} \mathrm{Significantly} \mathrm{different}$ from folic acid $(\mathrm{p}<0.05)$.

(a)

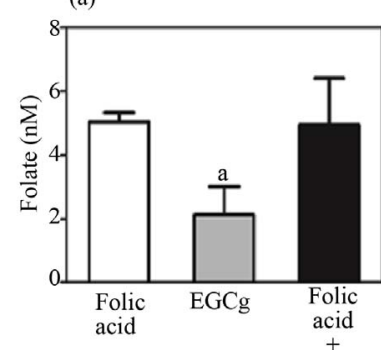

(c)

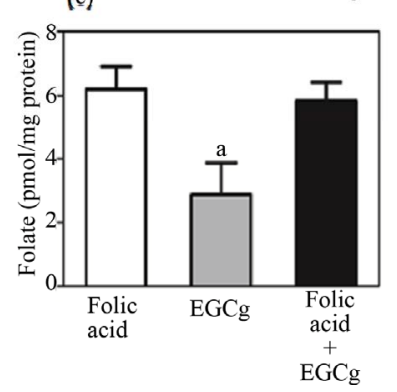

(b)

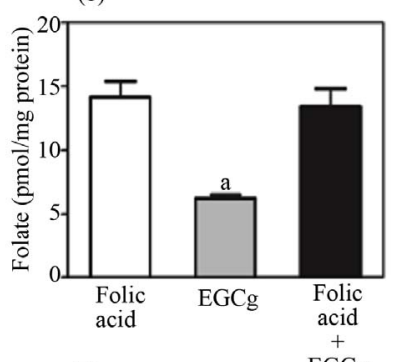

(d)

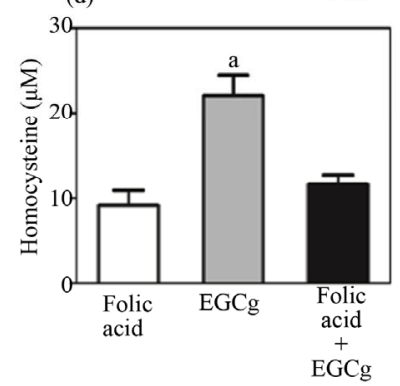

Figure 4. Influence of EGCg on repletion of folic acid in a folate depletion/repletion rat model. Rats fed a folate-deficient diet for 4 weeks were intragastrically given either folic acid (31 $\mu \mathrm{g} / \mathrm{kg}$ body weight), EGCg ( $8 \mathrm{mg} / \mathrm{kg}$ body weight) or folic acid + EGCg, while maintaining the same folatedeficient diet for 7 days. (a) Plasma folate level; (b) liver folate level; (c) bone marrow folate level; (d) plasma total homocysteine level. Values are mean $\pm S D, n=5$ - 6. ${ }^{\text {a Sig- }}$ nificantly different from folic acid group $(p<0.05)$.

low folate concentration. In the case of powdered green tea, the folate concentration in the test diet was $7.8 \%$. In the present study, the repletion effect with folic acid was consistently observed among plasma, liver, and bone marrow, while that with test food samples differed among these tissues. Changes in bone marrow folate status appeared delayed compared with those in plasma and liver, particularly for powdered green tea, which caused further depletion of bone marrow folate following the 7-day repletion period. These findings suggest that changes in bone marrow folate may be more evident later than examined here, and that green tea is not a good source of folate. Although we did not validate our test system against a human model, our rat model provides a practical initial approach to elucidating the bioavailability of green tea folate.

Erythrocyte folate level is well known as a stable indicator of body folate stores, and we confirmed this in the present study; erythrocyte folate level was quite stable even after 4 weeks of folate depletion. This stability is due to the relatively long life span of the erythrocyte (about 60 days in the rat [22]) after it emerges from the bone marrow and enters the bloodstream. On the other hand, the concentration of folate in bone marrow, which, like the liver, contains high amounts of folate [23], clearly changed due to depletion and repletion of folic acid, indicating that folate was taken up by the develop- 
ing erythrocytes in the bone marrow. The results indicate that an increase in bone marrow folate is a good indicator of the availability of both folic acid and natural folate. Moreover, an increase in the concentration of tissue folate was accompanied by a decrease in the concentration of plasma homocysteine when the repletion was performed with folic acid, but such a correlation was not observed with the food samples, particularly powdered green tea. This may be due to contributions of other substances within food samples that affect the metabolism of homocysteine. For example, tea catechin has been shown to reduce plasma homocysteine by increasing its catabolism in mice [24].

The reduced bioavailability of green tea folate might be related to the chemical structure of folates and the presence of reactive catechins in green tea. Wang et al. [25] reported that green tea catechins inhibited pancreatic phospholipase A2 and intestinal absorption of lipids in ovariectomized rats. Similarly, tea catechins, particularly $\mathrm{EGCg}$, might also inhibit folate conjugase, an enzyme needed to absorb natural folate. We did not clarify the chemical structure of folates within green tea, and it is possible that the folate might be in a highly polyglutamated form that needs to be broken down by conjugase into monoglutamate for uptake from the intestinal tract. In a randomized double-blind controlled study, intake of high-dose tea catechin (1069 mg/day) for 1 week as a capsule with normal diet in volunteers aged 40 - 63 years was associated with a decrease in folate levels and increase in total homocysteine levels in serum [26]. Therefore, inhibition of folate conjugase by tea catechin could be a mechanism of action that explains the reduced supply of natural folate in green tea.

An inhibitory effect of EGCg on dihydrofolate reducetase (DHFR) may be also involved in the reduced bioavailability of green tea folate. In Caco-2 cells, EGCg was shown to inhibit DHFR [10], which reduces folic acid to DHF and THF after absorption in the small intestine $[5,12]$. In a rat study in which animals were fed $2 \mathrm{mg}$ folic acid with various doses of green tea catechins for 42 days, Augustin et al. [13] reported that the plasma concentration of 5-methyl-tetrahydrofolate was reduced by the intake of green tea catechins $(5 \mathrm{~g} / \mathrm{kg}$ diet), but not when catechin dose was less than at $1 \mathrm{~g} / \mathrm{kg}$ diet. In our present study, powdered green tea samples contained catechin at $1.73 \mathrm{~g} / \mathrm{kg}$ diet. Thus, an inhibitory effect of tea catechin on DHFR may be another mechanism by which folate uptake into tissues is reduced during repletion with powdered green tea. In green tea, the content of EGCg is approximately $6-13 \mathrm{mg} / 100 \mathrm{~mL}$ [27]. If we consider a higher intake, such as 6 bottles of $500 \mathrm{~mL}$ of green tea beverage, this equates to an estimated EGCg intake of $8 \mathrm{mg} / \mathrm{kg}$ body weight. In the present study, pure EGCg at a dose of $8 \mathrm{mg} / \mathrm{kg}$ body weight did not affect the increase in tissue folate or decrease in plasma homocysteine when repletion was performed with folic acid, suggesting that absorption of folic acid is unaffected by low-dose EGCg. Therefore, folic acid supplementation of bottled green tea beverages may be a practical approach to minimize any negative effect of EGCg on folate status.

Periconceptional use of folic acid supplements is well known to reduce the risk of NTDs in infants [28]. In addition, serum folate levels were inversely related to tea consumption during pregnancy in Japan [11], and daily tea drinking during the periconceptional period was associated with an elevated risk of NTDs in a Chinese population [29]. Some young Japanese women who may become pregnant consume a green tea beverage with a high-strength tea catechin content for weight loss. Hence, infants born to these women may be at risk for NTDs. As shown in the present study, low-dose EGCg did not affect the supplementary effect of folic acid. Thus, it may be necessary to fortify with folic acid beverages containing tea catechin to counteract the negative effect of green tea on folic acid status.

In conclusion, we showed that natural folate in green tea was less bioavailable than that in other food sources, but EGCg at the dose found in green tea did not affect the uptake of folic acid into tissues in a folate depletion/repletion model. Our rat in vivo assay model with a 7-day repletion phase after 4 weeks' depletion appears suitable to study the different bioavailability of folate in food samples compared with folic acid.

\section{Acknowledgements}

This study was financially supported in part by a research grant from the Ministry of Health, Labour and Welfare, Japan.

\section{REFERENCES}

[1] Food and Nutrition Board, "Dietary Reference Intakes for Thiamin, Riboflavin, Niacin, Vitamin $\mathrm{B}_{6}$, Folate, Vitamin $\mathrm{B}_{12}$, Pantothenic Acid, Biotion, and Choline," National Academic Press, Washington DC, 1998.

[2] L. D. Botto, C. A. Moore, M. J. Khoury and J. D. Erickson, "Neural-Tube Defects," The New England Journal of Medicine, Vol. 341, No. 20, 1999, pp. 1509-1519. doi:10.1056/NEJM199911113412006

[3] M. Fenech, "Biomarkers of Genetic Damage for Cancer Epidemiology," Toxicology, Vol. 181-182, 2002, pp. 411416. doi:10.1016/S0300-483X(02)00480-8

[4] L. B. Bailey, G. C. Rampersaud and G. P. Kauwell, "Folic Acid Supplements and Fortification Affect the Risk for Neural Tube Defects, Vascular Disease and Cancer: Evolving Science," Journal of Nutrition, Vol. 133, No. 6, 2003, pp. 1961S-1968S.

[5] J. F. Gregory, "The Bioavailability of Folate," In: L. B. Bailey, Ed., Folate in Health and Disease, M. Dekker, 
New York, 1995, pp. 195-235.

[6] M. J. Whitrow, V. M. Moore, A. R. Rumbold and M. J. Davies, "Effect of Supplemental Folic Acid in Pregnancy on Childhood Asthma: A Prospective Birth Cohort Study," American Journal of Epidemiology, Vol. 170, No. 12, 2009, pp. 1486-1493. doi:10.1093/aje/kwp315

[7] Y. Clement, "Can Green Tea Do That? A Literature Review of the Clinical Evidence," Preventive Medicine, Vol. 49, No. 2-3, 2009, pp. 83-87. doi:10.1016/j.ypmed.2009.05.005

[8] N. Imaeda, C. Goto, Y. Tokudome, M. Ikeda, S. Maki and S. Tokudome, "Folate Intake and Food Sources in Japanese Female Dietitians," Environmental Health and Preventive Medicine, Vol. 7, No. 4, 2002, pp. 156-161. doi:10.1007/BF02897944

[9] N. C. Alemdaroglu, S. Wolffram, J. P. Boissel, E. Closs, H. Spahn-Langguth and P. Langguth, "Inhibition of Folic Acid Uptake by Catechins and Tea Extracts in Caco-2 Cells," Planta Medica, Vol. 73, No. 1, 2007, pp. 27-32. doi:10.1055/s-2006-951745

[10] E. Navarro-Peran, J. Cabezas-Herrera, F. Garcia-Canovas, M. C. Durrant, R. N. Thorneley and J. N. Rodriguez-Lopez, "The Antifolate Activity of Tea Catechins," Cancer Research, Vol. 65, No. 6, 2005, pp. 2059-2064. doi:10.1158/0008-5472.CAN-04-3469

[11] M. Shiraishi, M. Haruna, M. Matsuzaki, E. Ota, R. Murayama and S. Murashima, "Association between the Serum Folate Levels and Tea Consumption during Pregnancy," BioScience Trends, Vol. 4, No. 5, 2010, pp. 225230.

[12] N. C. Alemdaroglu, U. Dietz, S. Wolffram, H. Spahn-Langguth and P. Langguth, "Influence of Green and Black Tea on Folic Acid Pharmacokinetics in Healthy Volunteers: Potential Risk of Diminished Folic Acid Bioavailability," Biopharmaceutics \& Drug Disposition, Vol. 29, No. 6, 2008, pp. 335-348. doi:10.1002/bdd.617

[13] K. Augustin, J. Frank, S. Augustin, P. Langguth, V. Ohrvik, C. M. Witthoft, G. Rimbach and S. Wolffram, "Green Tea Extracts Lower Serum Folates in Rats at Very High Dietary Concentrations Only and Do Not Affect Plasma Folates in a Human Pilot Study," Journal of Physiology and Pharmacology, Vol. 60, No. 3, 2009, pp. 103-108.

[14] A. J. Clifford, N. D. Bills, J. M. Peerson, H. G. Muller, G. E. Burk and K. D. Rich, "A Depletion-Repletion Folate Bioassay Based on Growth and Tissue Folate Concentrations of Rats," Journal of Nutrition, Vol. 123, No. 5, 1993, pp. 926-932.

[15] K. Umegaki and T. Ichikawa, "Decrease in Vitamin E Levels in the Bone Marrow of Mice Receiving WholeBody X-Ray Irradiation," Free Radical Biology \& Medicine, Vol. 17, No. 5, 1994, pp. 439-444. doi:10.1016/0891-5849(94)90170-8

[16] K. Endoh, M. Murakami, R. Araki, C. Maruyama and K. Umegaki, "Low Folate Status Increases Chromosomal Damage by X-Ray Irradiation," International Journal of Radiation Biology, Vol. 82, No. 4, 2006, pp. 223-230. doi:10.1080/09553000600721817

[17] B. Frick, K. Schrocksnadel, G. Neurauter, B. Wirleitner,
E. Artner-Dworzak and D. Fuchs, "Rapid Measurement of Total Plasma Homocysteine by HPLC," Clinica Chimica Acta, Vol. 331, No. 1-2, 2003, pp. 19-23. doi:10.1016/S0009-8981(03)00076-7

[18] K. Aiso and T. Tamura, "Trienzyme Treatment for Food Folate Analysis: Optimal $\mathrm{pH}$ and Incubation Time for Alpha-Amylase and Protease Treatment," Journal of $\mathrm{Nu}$ tritional Science and Vitaminology (Tokyo), Vol. 44, No. 3, 1998, pp. 361-370. doi:10.3177/jnsv.44.361

[19] K. Umegaki, A. Sugisawa, K. Yamada and M. Higuchi, "Analytical Method of Measuring Tea Catechins in Human Plasma by Solid-Phase Extraction and HPLC with Electrochemical Detection," Journal of Nutritional Science and Vitaminology (Tokyo), Vol. 47, No. 6, 2001, pp. 402-408. doi:10.3177/jnsv.47.402

[20] A. J. Clifford, M. K. Heid, J. M. Peerson and N. D. Bills, "Bioavailability of Food Folates and Evaluation of Food Matrix Effects with a Rat Bioassay," Journal of Nutrition, Vol. 121, No. 4, 1991, pp. 445-453.

[21] M. Matsuzaki, M. Haruna, E. Ota, S. Sasaki, Y. Nagai and S. Murashima, "Dietary Folate Intake, Use of Folate Supplements, Lifestyle Factors, and Serum Folate Levels among Pregnant Women in Tokyo, Japan," Journal of Obstetrics and Gynaecology Research, Vol. 34, No. 6, 2008, pp. 971-979. doi:10.1111/j.1447-0756.2008.00821.x

[22] M. J. Derelanko, "Determination of Erythrocyte Life Span in F-344, Wistar, and Sprague-Dawley Rats Using a Modification of the $\left[{ }^{3} \mathrm{H}\right]$ Diisopropyl-Fluorophosphate ([ $\left.\left.{ }^{3} \mathrm{H}\right] \mathrm{DFP}\right)$ Method," Fundamental and Applied Toxicology, Vol. 9, No. 2, 1987, pp. 271-276. doi:10.1093/toxsci/9.2.271

[23] G. J. Ward and P. F. Nixon, "Modulation of Pteroylpolyglutamate Concentration and Length in Response to Altered Folate Nutrition in a Comprehensive Range of Rat Tissues," Journal of Nutrition, Vol. 120, No. 5, 1990, pp. 476-484.

[24] J. Hamelet, K. Demuth, J. Dairou, A. Ledru, J. L. Paul, J. M. Dupret, J. M. Delabar, F. Rodrigues-Lima and N. Janel, "Effects of Catechin on Homocysteine Metabolism in Hyperhomocysteinemic Mice," Biochemical and Biophysical Research Communications, Vol. 355, No. 1, 2007, pp. 221-227. doi:10.1016/j.bbrc.2007.01.142

[25] S. Wang, S. K. Noh and S. I. Koo, "Green Tea Catechins Inhibit Pancreatic Phospholipase A(2) and Intestinal Absorption of Lipids in Ovariectomized Rats," The Journal of Nutritional Biochemistry, Vol. 17, No. 7, 2006, pp. 492-498. doi:10.1016/j.jnutbio.2006.03.004

[26] T. Yoshikawa, H. Yamada, K. Matsuda, H. Nhno, Y. M. Sagesaka, T. Kakuda, K. Toyoizumi, K. Matsumoto, K. Kosuge, S. Uchida, S. Onoue, S. Yamada and K. Umegaki, "Effects of Short-Term Consumption of a Large Amount of Tea Catechins on Chromosomal Damage, Oxidative Stress Markers, Serum Lipid, Folic Acid, and Total Homocysteine Levels: A Randomized, Double-Blind, Controlled Study," Japanese Journal of Clinical Pharmacology and Therapeutics, Vol. 43, No. 1, 2012, pp. 9-16. doi:10.3999/jscpt.43.9

[27] K. Umegaki, T. Esashi, M. Tezuka, A. Ono, A. Sano and 
I. Toimita, "Determination of Tea Catechins in Food by HPLC with an Electrochemical Detector," Food Hygiene and Safety Science, Vol. 37, No. 2, 1996, pp. 77-82. doi:10.3358/shokueishi.37.77

[28] M. Eichholzer, O. Tonz and R. Zimmermann, "Folic Acid: A Public-Health Challenge," Lancet, Vol. 367, No. 9519,
2006, pp. 1352-1361.

doi:10.1016/S0140-6736(06)68582-6

[29] R. Ye, A. Ren, L. Zhang, Z. Li, J. Liu, L. Pei and X. Zheng, "Tea Drinking as a Risk Factor for Neural Tube Defects in Northern China," Epidemiology, Vol. 22, No. 4 2011, pp. 491-496. doi:10.1097/EDE.0b013e31821b4526

\section{Abbreviations}

EGCg: epigallocatechin gallate; DHFR: dihydrofolate reductase;

DHF: 7,8-dihydrofolate;

THF: 5,6,7,8-tetrahydrofolate;

NTDs: neural tube defects. 